Manconi PE, Del Giacco SR. TH17 cells are increased in the peripheral blood of patients with SAPHO syndrome. Autoimmunity. 2014 Sep;47(6):389-94. doi: 10.3109/08916934.2014.906582. Epub 2014 Apr 10.

Disclosure of Interest: None declared

DOI: 10.1136/annrheumdis-2017-eular.4360

\section{AB0040 IMMUNE MODULATORY EFFECTS OF MESENCHYMAL STEM CELL TO MONONUCLEAR CELLS FROM PATIENTS WITH ACTIVE ADULT ONSET STILL'S DISEASE}

I.W. Sohn ${ }^{1}$, H.-J. Jeong ${ }^{2}$, G.Y. Ahn ${ }^{1}$, M.J. Kim ${ }^{1}$, H. Kim ${ }^{1}$, S. Kang ${ }^{1}$, D.H. Yoo ${ }^{1}$ ${ }^{1}$ Rheumatology, Hanyang University Hospital for Rheumtic diseases, Seoul; ${ }^{2}$ Rheumatology, Keimyung University Dongsan Medical Center, Daegu, Korea, Republic Of

Background: Adult onset Still's disease (AOSD) is an inflammatory disorder of unknown etiology, which is accompanied by increased levels of serum proinflammatory cytokine. Mesenchymal stem cells (MSCs) have immunomodulatory capacities and might be a promising therapeutic option in the treatment of refractory autoimmune diseases. Both cell-to-cell contact and the release of soluble factors mediate immune modulatory functions of MSCs.

Objectives: We aimed to determine if MSCs could modulate serum cytokine level in patients with active untreated AOSD, either through paracrine secretion or via direct contacts with the MSCs.

Methods: Human peripheral blood mononuclear cells (hPBMCs) from 6 patients with active AOSD were co-cultured for 72 hours with human MSCs (hMSCs at a ratio of 10 to 1). We compared the cytokine levels before and after direct or indirect (transwell cultures) exposition to activated mononuclear cells (LPS, $10 \mathrm{ng} / \mathrm{ml}$ ) or T cell-inducing conditions (anti-CD3 [5 $\mu \mathrm{g} / \mathrm{ml}]$, anti-CD28 [5 $\mu \mathrm{g} / \mathrm{ml}]$, recombinant human $\mathrm{IL}-2[5 \mathrm{ng} / \mathrm{ml}])$. Cytokine levels were detected by multiplex cytokine detection kit by flow cytometry, or ELISA with culture supernatant. In vitro platform for studying the effects of MSCs on individual cytokines, the Wilcoxon signed-rank test was employed for comparison of serum cytokine levels.

Results: Treatment of mononuclear cells with hMSCs resulted in significant reduction of mean TNF- $\alpha$ level (mean $463.4 \mathrm{pg} / \mathrm{ml}$ vs $137.8 \mathrm{pg} / \mathrm{ml}, \mathrm{p}<0.05$ ) and IL-1 $\beta$ (mean $1887.1 \mathrm{pg} / \mathrm{ml}$ vs $1127.9 \mathrm{pg} / \mathrm{ml}, \mathrm{p}<0.05$ ). When the $\mathrm{hMSCs}$ were present during the T-cell differentiation, there was a significant decrease in the mean secreted TNF- $\alpha$ (mean $10953.5 \mathrm{pg} / \mathrm{ml}$ vs $454.9 \mathrm{pg} / \mathrm{ml}, \mathrm{p}<0.05$ ), IFN- $\gamma$ (mean $14301.0 \mathrm{pg} / \mathrm{ml}$ vs $5090.4 \mathrm{pg} / \mathrm{ml}, \mathrm{p}<0.05$ ) and slL-2 receptor (mean $3550.8 \mathrm{pg} / \mathrm{ml}$ vs $2506.4 \mathrm{pg} / \mathrm{ml}, p<0.05$ ). On the contrary, level of TGF- $\beta$ was significantly increased (mean $4088.8 \mathrm{pg} / \mathrm{ml}$ vs $5104.8 \mathrm{pg} / \mathrm{ml}, \mathrm{p}<0.05)$. But, there was a significant increase in the amount of IL-6 (mean $2215.5 \mathrm{pg} / \mathrm{ml}$ vs 25130.6 $\mathrm{pg} / \mathrm{ml}, \mathrm{p}<0.05$ ) and IL-17 $\alpha$ (mean $1357.0 \mathrm{pg} / \mathrm{ml}$ vs $2453.6 \mathrm{pg} / \mathrm{ml}, \mathrm{p}<0.05)$. Two chamber experiments also showed similar pattern of cytokine modulation.

Conclusions: This preliminary experiment demonstrated that MSCs can modulate cyokine profiles of AOSD mononuclear cells by decreasing pro-inflammatory cytokines, and increasing anti-inflammatory cytokine such as TGF- $\beta$. However, up-regulation of IL-6 and IL-17 might be a hurdle to overvome in the clinical application of MSCs in AOSD patients.

References:

[1] Serum cytokine profiles in patients with Adult onset Still's disease. J Rheumatol. 2003 Nov;30(11):2422-7.

[2] Human mesenchymal stem cells modulated allogeneic immune cell responses. Blood. 2005 Feb 15;105(4):1815-22. Epub 2004 Oct 19.

Acknowledgements: none.

Disclosure of Interest: None declared

DOI: 10.1136/annrheumdis-2017-eular.5719

\section{AB0041 LARGE VESSEL VASCULITIS INDUCED BY CANDIDA ALBICAN WATER-SOLUBLE-FRACTION (CAWS) IN THE C57BL/6J MOUSE MODEL IS ASSOCIATED WITH OVEREXPRESSION OF IL-6, TNF- $\alpha$, AND IL-10 WITH MODEST CHANGE IN SOCS-1}

J.M. Springer ${ }^{1}$, M. Zhang ${ }^{2}$, D. Smith ${ }^{1}$, N. Miura ${ }^{3}$, N. Ohno ${ }^{3}$, O. Tawfik ${ }^{4}$, M. Maz ${ }^{1}$, K. Dileepan ${ }^{1} .{ }^{1}$ Allergy, Immunology and Rheumatology; ${ }^{2}$ Department of Orthopedics, Kansas University Medical Center, Kansas City, United States;

${ }^{3}$ Department of Pharmacy and Life Sciences, Tokyo University, Hachioji, Japan;

${ }^{4}$ Department of Pathology and Laboratory Medicine, Kansas University Medical Center, Kansas City, United States

Background: We have previously demonstrated that mast cell degranulation acutely downregulates lipopolysaccharide induced aortic expression and serum levels of IL- 6 in vivo. This is accompanied by aortic upregulation of suppressor of cytokine signaling-1 (SOCS-1) gene expression ${ }^{1}$. This effect is not seen in histamine $\mathrm{H} 1$ receptor-knockout mice suggesting that mast cell-derived histamine is a key mediator involved in IL-6 homoeostasis ${ }^{2}$. Mice injected with Candida albican water-soluble-fraction (CAWS) have been shown to develop coronary and aortic vasculitis ${ }^{3}$. Our long-term objective is to determine the pathogenic mechanism of large vessel vasculitis (LVV).

Objectives: The aim of this pilot study was to replicate and develop a working mouse model to determine the regulatory role of mast cells in LVV.

Methods: Eight to ten weeks-old male C57BI6/J mice were randomly distributed into two groups [CAWS, $\mathrm{N}=8$; and Control, $\mathrm{N}=8$ ] and were injected i.p. daily for
5 days with either CAWS in normal saline ( $2 \mathrm{mg} /$ day/mouse) or normal saline alone (controls). All mice were sacrificed 30 days after the 5 th injection. We examined serum levels of IL- 6 and TNF- $\alpha$, as well as aortic tissue expressions of IL-6, TNF-a, IL-10 and SOCS-1 mRNA. Heart and aortic sections were evaluated for inflammation and mast cells after staining with $\mathrm{H} \& \mathrm{E}$ and toluidine blue, respectively.

Results: Treatment of mice with CAWS for 5-consecutive days led to overexpression of IL-6, TNF-a and IL-10 genes in the aortic tissue with modest upregulation of SOCS-1. At the root of the aorta, all animals in the CAWS group had intense inflammatory infiltrates composed of mixed acute and chronic inflammatory cells. There is also evidence of vasculitis in the coronary arteries. In contrast, none of the control mice had any evidence of aortic inflammation or vasculitis. Serum IL-6 concentrations were below detectable levels in both controls and CAWS-treated mice whereas TNF-a levels were elevated in 3 out of 8 mice in the CAWS group. There were no signs or increased presence of intact or degranulating mast cells in the area of inflammation.

Conclusions: These results suggest that CAWS-induced LVV involves acute and chronic inflammatory response and vascular tissue expression of both pro- and anti-inflammatory cytokines and SOC-1. Detailed kinetic studies are warranted to determine the optimum windows of peak inflammatory response and the expression of these genes to understand the pathobiology of CAWS-induced LVV. References:

[1] Springer J, Raveendan V, Smith D, et al. [abstract] Ann Rheum Dis 2014; 73:112-113

[2] Raveendran V, Springer J, Smith D, et al. [abstract]. Arthritis Rheumatol 2015; 67(suppl 10).

[3] Miura N, Shingo Y, Adachi Y, et al. Immunopharmacol Immunotoxicol 2004; 26(4):527-43.

Acknowledgements: Supported by Basic Science Development Award from Department of Medicine at the University of Kansas.

Disclosure of Interest: None declared

DOI: 10.1136/annrheumdis-2017-eular.4884

\section{AB0042 HIGH EXPRESSION OF S100 CALGRANULINS GENES IN PERIPHERAL BLOOD MONONUCLEAR CELLS OF PATIENTS WITH TAKAYASU ARTERITIS}

J. Kabeerdoss, R. Goel, H. Mohan, D. Danda. Department of Rheumatology, CHRistian Medical College, Vellore, India

Background: Takayasu arteritis (TA) is inflammatory disorder that affects aorta and its branches. Toll-like receptors (TLR) 1 to 4 are highly expressed in aorta (1). Activation of TLR4 causes transmural arteritis in human temporal artery-SCID chimera model (2). Ligand responsible for TLR4 activation is not known in TA.

Objectives: Aim of the study is to examine the expression of TLR4 and its endogenous ligands in peripheral blood mononuclear cells (PBMCs) of patient with TA.

Methods: RNA from PBMCs of 24 TA patients and 19 sex and age matched healthy controls were extracted. The mRNA expression of various endogenous TLR4 ligands, TLR4, RAGE, interleukin-6 (IL-6) and IL-8 were quantified in real time PCR using specific primers and SYBR Green qPCR master mix. Serum S100A8/A9 and S100A12 levels were measured using commercial ELISA kits. S100A8/A9 and S100A12 were measured in cell culture supernatant of un-stimulated and lipopolysaccharides (LPS) stimulated PBMCs, cultured for 4 hours. t-test was used to compare between the groups. $\mathrm{P}<0.05$ was considered as statistically significant.

Results: The mRNA of S100A8, S100A9, S100A12 and TLR4 were highly expressed in TA as compared to healthy controls, while RAGE, HSP70 and IL-6 had lower expression in TA. No difference in serum levels of S100A8/A9 and S100A12 was noted between TA and healthy controls. LPS induced high secretion of both S100A8/A9 and S100A12 levels in both TA and healthy controls (Figure-1). However, the stimulatory response in healthy controls [2.88 (1.7-3.53) fold] was significantly higher as compared to TA [1.345 (1-1.82) fold; $p<0.05]$ as measured by delta S100A12 (LPS/unstimulated control). Numerically delta S100A8/A9 was also higher in healthy controls [2.04 (1.7-5.6) fold] as compared to TA $[1.38$ (1.09-3.6) fold; $p=0.129]$.

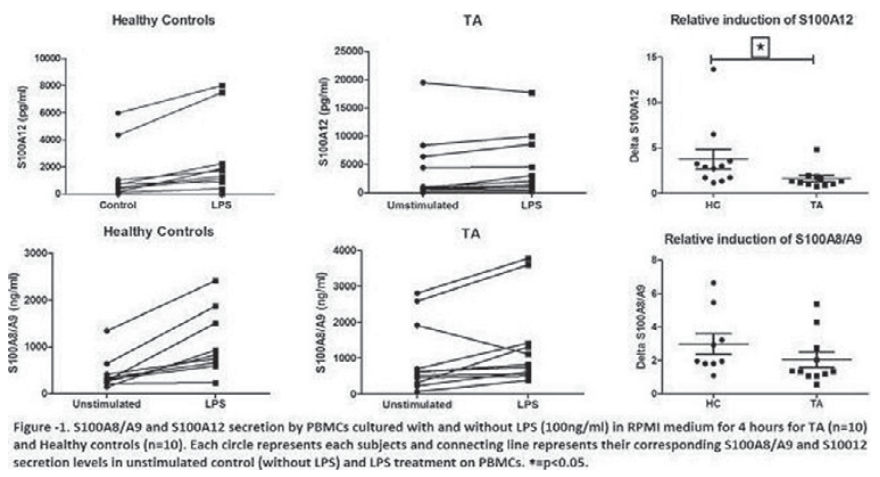


Conclusions: mRNA expression of S100A8, S100A9, S100A12 and TLR4 in PBMCs of TA patients were higher as compared to healthy controls. Despite this, S100A12 secretion was lower in TA as compared to healthy controls upon LPS challenge.

References:

[1] Pryshchep O, Ma-Krupa W, Younge BR, et al (2008) Vessel-specific Toll-like receptor profiles in human medium and large arteries. Circulation 118:12761284.

[2] Deng J, Ma-Krupa W, Gewirtz AT, et al (2009) TLR4 and TLR5 induce distinct types of vasculitis. Circ Res 104:488-495.

Acknowledgements: This study was funded by grants-in-aid from Science and Engineering Research Board (SERB), Department of Science and Technology (DST), Government of India under young investigator scheme to JK (SB/YS/LS14/2014).

Disclosure of Interest: None declared

DOI: 10.1136/annrheumdis-2017-eular.5682

\section{AB0043 TLR4 INHIBITION REDUCES MOVEMENT-INDUCED NOCICEPTION AND ATF-3 EXPRESSION IN EXPERIMENTAL OSTEOARTHRITIS}

J. Ferreira-Gomes ${ }^{1,2,3}$, M.M. Garcia ${ }^{4}$, D. Nascimento ${ }^{1,2,3}$, L. Almeida ${ }^{1,2,3}$, E. Quesada ${ }^{5}$, C. Goicoechea ${ }^{4}$, J. Castro-Lopes ${ }^{1,2,3}$, F. Neto ${ }^{1,2,3} \cdot{ }^{1}$ Departamento de Biomedicina - Unidade de Biologia Experimental, Faculdade de Medicina da Universidade do Porto: ${ }^{2}$ Instituto de Investigação e Inovação em Saúde, Universidade do Porto; ${ }^{3}$ IBMC-Instituto de Biologia Molecular e Celular, Universidade do Porto, Porto, Portugal; ${ }^{4}$ Area de Farmacologia, Facultad de Ciencias de la Salud, Universidad Rey Juan Carlos. Unidad Asociada URJCIQM-CSIC, Alcorcon; ${ }^{5}$ Instituto de Química Médica, Consejo Superior de Investigaciones Científicas. Unidad Asociada URJC- IQM-CSIC, Madrid, Spain

Background: Toll-like receptor 4 (TLR4) is a pattern recognition receptor involved in the initiation of inflammatory responses to control pathogen infections, but is also a "danger-sensing" receptor that recognizes host-derived endogenous molecules called damage-associated molecular patterns (DAMPs). The role of TLR4 in rheumatic diseases is becoming evident, as well as its potential role as a therapeutic option.

Objectives: The aim of this study was to evaluate the effect, both on articular histopathology and pain behaviour, of a TLR4 antagonist (TLR4-A1) on an experimental model of OA. The effect of the TLR4-A1 on the activating transcription factor-3 (ATF-3) signalling pathway was also assessed.

Methods: OA was induced in adult Wistar rats through an intra-articular injection of $2 \mathrm{mg}$ of sodium mono-iodoacetate (MIA) into the left knee. Control animals received a similar injection with saline. TLR4-A1 $(10 \mathrm{mg} / \mathrm{kg})$, synthesized by $\mathrm{Dr}$. Quesada from a compound previously described by the Peri Laboratory (Piazza et al., 2009), was intraperitoneally administered, daily, from days 14 to 28 after $\mathrm{OA}$ induction. Under the same procedure a control group of animals received the vehicle. Movement- and loading- induced nociception was evaluated in all animals, by the Knee-Bend and CatWalk tests, before and after TLR4-A1 or vehicle administration, at several time-points. Animals were sacrificed 28 days after OA induction. L3-L5 Dorsal Root Ganglia (DRG) were used for immunohistochemistry for TLR4 and ATF-3, spinal cords were immunoreacted for TLR4 and knee joints were processed for histopathological evaluation.

Results: Antagonism by TLR4-A1 significantly reduced the nociceptive behavior of $\mathrm{OA}$ animals both in the Knee-Bend and Catwalk tests. The effect was immediately observed 1 day after TLR4-A1 administration, but became more evident 4 days later, maintaining thereafter. No improvement in the cartilage histology was observed. The increased ATF-3 expression observed in DRG of OA animals was significantly reduced by TLR4-A1. On the contrary, TLR4 expression slightly increased after antagonist administration both at DRG and superficial dorsal horn levels.

Conclusions: Chronic treatment with TLR4-A1 showed an antinociceptive effect on $\mathrm{OA}$ animals, not related to articular histopathological improvement, possibly through an ATF-3 dependent mechanism.

References:

[1] Piazza M, Rossini C, Fiorentina SD, Pozzi C, Cornelli F, Bettoni I, Fusi P, Costa $B$ and Peri F. Glycolipids and Benzylammonium Lipids as Novel Antisepsis Agents: Synthesis and Biological Characterization. J Med Chem 2009, 52, 1209-1213.

Acknowledgements: Granted by FEDER funds through COMPETE - Programa Operacional Factores de Competitividade (FCOMP-01-0124-FEDER-021359) and by National Funds through FCT - Fundação para a Ciência e a Tecnologia (PTDC/SAU-NSC/119986/2010); and by Ministerio de Economia y Competitividad (SAF2012-40075-C02-02).

Disclosure of Interest: None declared

DOI: 10.1136/annrheumdis-2017-eular.2878

\section{AB0044 THE INHIBITORY EFFECTS OF TACROLIMUS ON GLIOSTATIN PRODUCTION IN RA SYNOVIOCYTES}

K. Ikuta ${ }^{1}$, Y. Waguri-Nagaya ${ }^{2}$, T. Yamagami ${ }^{3}$, N. Tatematsu ${ }^{3}$, Y. Kawaguchi ${ }^{3}$, Y. Oguri ${ }^{3}$, T. Terazawa ${ }^{1}$, M. Kobayashi ${ }^{3}$, K. Asai ${ }^{4}$, T. Otsuka ${ }^{3} .{ }^{1}$ Orthopaedic
Surgery, Daido Hospital; ${ }^{2}$ Joint Surgery for Rheumatic Diseases: ${ }^{3}$ Orthopaedic Surgery; ${ }^{4}$ Molecular Neurobiology, Nagoya City University Graduate School of Medical Sciences, Nagoya, Japan

Background: Gliostatin (GLS) is known to have angiogenic and arthritogenic activities ${ }^{1}$. We also reported a decrease in serum GLS levels in RA patient responders treated with conventional synthetic disease-modifying anti-rheumatic drugs (csDMARDs) ${ }^{2}$. Tacrolimus (TAC), an orally available calcineurin inhibitor, is a potent immunosuppressant. The efficacy of TAC monotherapy and the combination therapy with TAC and methotrexate in the treatment of RA has been previously described ${ }^{3}$. Although the principal TAC action is thought to be the inhibition of $T$ cell activation, its beneficial effect on RA synoviocytes has not been yet elucidated.

Objectives: To determine the inhibitory effects of TAC on GLS production in RA, we investigated the modulation of serum GLS by TAC therapy and the effect of TAC on the production of GLS in cultured fibroblast-like synoviocytes (FLSs).

Methods: Serum samples were collected from eleven RA patients with active disease at baseline and after 12 weeks of TAC treatment. These RA patients had a history of unsatisfied response with at least one csDMARD or biological DMARD. Serum concentrations of GLS and matrix metalloproteinase (MMP)3 were measured by enzyme immunoassay (EIA). Synovial specimens were obtained from RA patients at the time of total knee arthroplasty. FLSs were cultured and stimulated by TNF alfa with or without TAC. The expression levels of GLS were determined using RT-PCR and EIA. MMP-3 protein in conditioned media was measured by using EIA.

Results: Six patients fulfilled good and moderate responder and the other five patients fulfilled no responder with EULAR response criteria. DAS28, serum GLS, CRP and MMP-3 were significantly down-regulated in TAC responders. In RA FLSs, GLS mRNA and protein were significantly induced after treatment with TNF alfa alone (GLS mRNA 21.9-fold, protein 1.5-fold compared to control). These inductions were suppressed by TAC in a dose-dependent manner. MMP-3 protein was induced by TNF alfa and was similarly suppressed by TAC in a dose-dependent manner (MMP-3 protein 2.9-fold compared to control).

Conclusions: This study is the first to demonstrate that TAC down-regulates GLS mRNA and protein in FLSs treated by TNF alfa. Our data suggests that the beneficial effect of TAC in RA might be due to, at least in part, to anti-angiogenic and anti-arthritogenic activity following the down-regulation of GLS.

References:

[1] Asai K, et al. High concentration of immunoreactive gliostatin/ platelet-derived endothelial cell growth factor in synovial fluid and serum of rheumatoid arthritis. Clin Chim Acta 1993;218:1-4.

[2] Kusabe $\mathrm{T}$, et al. The inhibitory effect of disease-modifying anti-rheumatic drugs and steroids on gliostatin/platelet-derived endothelial cell growth factor production in human fibroblast-like synoviocytes. Rheumatol Int 2005;25:625630.

[3] Kremer JM, et al. Tacrolimus in rheumatoid arthritis patients receiving concomitant methotrexate: a six-month, open-label study. Arthritis Rheum 2003;48:2763-2768.

Acknowledgements: This research was supported by Grand-in-Aid for Scientific Research(C) (26462309) and 16K10913 from the Japan Society for the Promotion of Science.

Disclosure of Interest: K. Ikuta: None declared, Y. Waguri-Nagaya Grant/research support from: Biomet Japan, Inc, Chugai Pharmaceutical Co., Ltd., Astellas Pharma Inc., Merck Sharp \& Dohme Co., AbbVie Japan Co., Ltd., Ono Pharmaceutical Co., Ltd., T. Yamagami: None declared, N. Tatematsu: None declared, Y. Kawaguchi: None declared, Y. Oguri: None declared, T. Terazawa: None declared, M. Kobayashi: None declared, K. Asai: None declared, T. Otsuka: None declared DOI: 10.1136/annrheumdis-2017-eular.2527

\section{AB0045 IL-17 INDUCED GLUCOCORTICOID INSENSITIVITY MIGHT BE DEPENDENT ON THE REDUCED 11BETA-HSD1 ENZYME ACTIVITY}

M. Vitiello ${ }^{1}$, V. Kunnathully ${ }^{1}$, G. Orsolini ${ }^{1}$, O. Viapiana ${ }^{1}$, F. Poli ${ }^{1}$, A. Mattè $^{2}$, L. De Franceschi ${ }^{2}$, L. Idolazzi ${ }^{1}$, D. Gatti ${ }^{1}$, M. Rossini ${ }^{1} .{ }^{1}$ Rheumatology Unit; ${ }^{2}$ Internal Medicine Section, University of Verona, Verona, Italy

Background: It has been demonstrated that IL-17A is able to induce GC insensitivity. Although several studies have reported the role of IL-17 in GC insensitivity the mechanism underlying remains still largely unclear.

Objectives: To understand the effects of interleukin-17 (IL-17) on the enzyme


monocytes, CD14 and CD16.

Methods: Peripheral Blood Mononuclear Cells (PBMCs) were isolated from 5 healthy donors and were sorted into CD14 and CD16 subpopulations using cell sorting. Effect of IL-17 on $11 \beta$-HSD1 enzyme activity was measured in terms of conversion of cortisone to cortisol in sorted and unsorted monocytes using Homogeneous Time-Resolved Fluorescence (HTRF). The direct involvement of $11 \beta$-HSD1 in the conversion of cortisone to cortisol was confirmed using carbenoxolone, an inhibitor of $11 \beta$-HSD1.

Results: Monocytes showed a concentration-dependent decrease in the $11 \beta$ HSD1 enzyme activity when incubated with increasing concentrations of IL-17. CD14 and CD16 cells stimulated similarly with IL-17 showed a significant 